\title{
Privacidad frente al uso de drones con fines periodísticos. Marco regulador de Estados Unidos y Europa
}

\author{
Privacy in the use of drones for journalistic purposes. \\ Regulatory frameworks of the United States and Europe
}

\author{
Aguado-Guadalupe, G. ${ }^{1}$ \\ Recibido: 13-08-2020 - Aceptado: 30-01-2021 \\ https://doi.org/10.26441/RC20.1-2021-A1
}

\begin{abstract}
RESUMEN: El artículo analiza la repercusión en la actividad periodística de las medidas reguladoras aprobadas por parte de Estados Unidos y Europa para proteger la privacidad frente al uso de drones. Se estudian las similitudes y diferencias entre las disposiciones adoptadas. Se observa que en Estados Unidos se opta por recomendaciones, donde prevalece la voluntariedad del usuario del dron frente al derecho de terceros a la privacidad. Si bien hay excepciones, como los casos de los estados de Texas y California, donde se considera un delito contra la privacidad el uso de drones sin la debida autorización. En Europa, la normativa es aplicable a todos los países miembros, y el sistema es más garantista, considerando los principios de necesidad y transparencia.
\end{abstract}

Palabras clave: dron; periodismo; privacidad; legislación; Estados Unidos; Europa.

ABSTRACT: This article analyzes the repercussions on journalistic activity of the regulatory measures adopted by the United States and Europe to protect privacy in the use of drones. Similarities and differences between the adopted regulations are evaluated. It is observed that in the United States recommendations are generally chosen, in which drone user's willingness prevails over third parties' right to privacy. However, there are exceptions, such as the cases of the states of Texas and California, where the use of drones without proper authorization is considered a violation of the right to privacy. In Europe, the regulations are applicable to all member countries, and the system provides more guarantees, considering the principles of necessity and transparency.

Keywords: drone; journalism; privacy; legislation; United States; Europe.

\footnotetext{
${ }^{1}$ Guadalupe Aguado-Guadalupe es Doctora en Ciencias de la Información por la Universidad Complutense de Madrid. Actualmente es Profesora Titular del Departamento de Comunicación en la Universidad Carlos III de Madrid, donde imparte la asignatura de Organización y Gestión de la Empresa Informativa. Es miembro del grupo de investigación Periodismo y Análisis Social: Evolución, Efectos y Tendencias (PASEET). maguado@hum.uc3m.es, http://orcid.org/0000-0001-7314-2403
} 


\section{Introducción ${ }^{2}$}

El debate sobre libertad de información, seguridad y privacidad, presente a la hora utilizar drones con fines periodísticos, ha adquirido fuerza al incrementarse el uso de dicha tecnología. Ello ha llevado a reivindicar normativas que permitan compaginar el derecho a la privacidad y el acceso a la información. El objetivo es minimizar el daño a la hora de obtener información por parte de los periodistas, quienes podrían hacer uso de medios de vigilancia invasivos para captar imágenes y amenazar la esfera privada.

Precisamente, la protección de privacidad, ante la utilización de drones, es lo que ha llevado a los periodistas en Estados Unidos a pedir a la Administración de la Aviación Federal (FAA) que adopte normas al respecto. Con ello se busca evitar situaciones como la producida en 2014, cuando The New York Times y otros medios de comunicación acusaron a la FAA de violar sus derechos de Primera Enmienda, al prohibir el empleo de drones para hacer fotografías con fines noticiosos.

En 2015 se pidió a los grandes medios audiovisuales que intervinieran para luchar por el uso de drones con fines periodísticos, ante las legislaciones rígidas (Holton, Lawson y Love, 2015). En esta línea, la Professional Society of Drone Journalists ha trabajado con cadenas como la BBC en Reino Unido, la ABC en Australia y la NRK en Noruega, para establecer normas éticas, educativas y tecnológicas sobre la utilización de drones con fines informativos (Gynnild, 2014).

El debate sobre privacidad y uso de tecnología se remonta en Estados Unidos a finales del siglo XIX (Saldaña, 2012). Se considera un hito fundacional de la privacidad americana el artículo "The Right to Privacy", de Warren y Brandeis en 1890, quienes manifestaron la necesidad de definir un principio que pueda invocarse para proteger la vida privada del individuo frente a la invasión de la prensa o poseedores de aparatos de grabación. Principio que se materializa en el derecho a la privacidad (Right to Privacy) (Saldaña, 2012). Posteriormente, la teoría del Right to Privacy fue formulada por Prosser (1960), quien diferenció cuatro estadios de invasión: intrusión en la soledad de la vida de una persona o en sus asuntos privados; divulgación de hechos embarazosos que afectan a la persona; publicidad que podría desprestigiar a la persona ante la opinión pública, y apropiación del nombre o imagen de otra persona.

Con el desarrollo tecnológico se ha reclamado un nuevo ámbito de protección de la privacidad, la "informational privacy". Ello ha llevado a definir el derecho a la privacidad como el poder de controlar el flujo de información personal (Fried, 1968). Autores como Miller (1971) han afirmado que el principal atributo de un efectivo derecho a la privacidad es la capacidad de la persona de controlar el flujo de información que le concierne. Si bien, ha de tenerse presente que la privacidad es un concepto complejo (Solove, 2008); amplio, que va más allá del derecho a la intimidad vigente en Europa (Whitman, 2004); y "con múltiples aristas en su significado" (Pérez Miras, 2018, p.2).

La privacidad ha sido ubicada, por autores como Solove (2002), dentro de un contexto cambiante. Cohen (2000) la vincula con el desarrollo de la autonomía individual y la ve como un valor social. Asimismo, autores como Schwartz (1999) relacionan su protección al desarrollo de la personalidad y la consideran esencial en las sociedades democráticas. A efectos de su regulación, mientras que en Europa se establecen normas generales y unificadas para todos los estados miembros, en Estados Unidos su regulación es sectorial, con diferentes estatutos para el ámbito público y el privado (Schwartz, 2013). En Estados Unidos hay corrientes doctrinales que abogan por una menor regulación de los poderes públicos y una mayor autorregulación personal de la

\footnotetext{
2 El presente trabajo se enmarca en el proyecto de investigación "Ecología de los medios y tecnologías emergentes: cibercultura, interdisciplinariedad e investigación aplicada. Estudio e innovación de modelos multimedia y digitales", financiado por Santander-Universidad Complutense de Madrid.
} 
privacidad (Goldman, 2002). También hay posiciones que mezclan la regulación pública al uso con la autorregulación (Hirsch, 2006).

Como indica Pérez Miras (2018), en Estados Unidos la privacidad y su derecho de protección se perfilan bien desde el punto de vista constitucional, bien desde el derecho mercantil, a través del desarrollo federal de normas, e incluso desde el derecho contractual y de propiedad. En Europa las perspectivas doctrinales sobre la privacidad gozan de un mayor consenso. Ello, como indica Pérez Miras (2018), es en parte por la tradición asimilada más cercana en el tiempo en su consideración como derecho fundamental y, por otra parte, "por la propia construcción jurisprudencial que va modelando y afianzando su contenido desde una estructura judicial multinivel europea" (Pérez Miras, 2018, p.2). La regulación europea establece unos límites más estrictos que la estadounidense, por ejemplo, para la recopilación y el uso de datos (Suárez-Gonzalo, 2017).

El presente artículo aborda las medidas reguladoras para proteger la privacidad ante la irrupción de la tecnología dron en el periodismo; buscando conocer, comprender y comparar (Pieters, 2009). Para ello, se ha realizado un análisis comparado entre Europa y Estados Unidos. Se pretende apreciar las diferentes soluciones a una misma situación (Sacco, 1991), así como identificar aquello que sobresale en la similitud (Zweigert y Kötz, 1998).

Los objetivos de la investigación son:

1. Conocer las diferentes soluciones por parte de Estados Unidos y Europa para la protección de la privacidad frente al uso de drones con fines periodísticos.

2. Observar si las medidas adoptadas en las diferentes normativas son o no de obligado cumplimiento.

3. Ver si hay excepciones profesionales en las diferentes normativas y si se contemplan excepciones para el uso de drones con fines periodísticos.

Teniendo presente que en el Derecho comparado se parte del supuesto de que hay una multiplicidad de soluciones normativas para un mismo problema o situación (Saco, 1991), se parte de la hipótesis de que en el uso de drones con fines periodísticos las soluciones de Estados Unidos y Europa son distintas. En dichos posicionamientos inciden las diferentes concepciones sobre la noción de privacidad en uno y otro territorio (Saldaña, 2007). Esas peculiaridades repercuten, a su vez, en el equilibrio entre el derecho a informar y el respeto a la privacidad (Padgett, 1985).

\section{Marco referencial}

El uso de drones con fines informativos ha venido siendo objeto de estudio por autores como Waite (2013), quien opinaba que la principal aplicación de los drones en periodismo era la obtención de imágenes de difícil cobertura, como pueden ser las manifestaciones, las catástrofes naturales o los conflictos bélicos.

Corcoran (2014), corresponsal internacional de la Australian Broadcasting Corporation, veía el uso de drones en cuatro supuestos: grandes conflictos, disturbios sociales, manifestaciones y cobertura de desastres. Pero la evolución de dichos dispositivos en cuanto a miniaturización, abaratamiento de costes y facilidad de manejo, ha facilitado su uso por parte de los periodistas con muy diferentes objetivos (Torres-Simón, 2016).

Goldberg, Corcoran y Picard (2013), señalan que el periodismo con drones permite la obtención de imágenes sin que el periodista sea observado y en lugares de difícil acceso, lo cual es de gran utilidad para el periodismo de investigación. Al mismo tiempo, posibilita generar datos para hacer 
historias de investigación en profundidad (Ciobanu, 2016), ofreciendo contenido de alto valor documental (Fernández-Barrero, 2018).

Gynnilds (2014) ve ventajas evidentes y puntualiza que hay que acoplar el empleo de drones a los valores y prácticas del periodismo profesional. Aspectos que también son puestos de manifiesto por Fernández-Barrero (2018), quien reivindica la importancia de adaptar esta tecnología con las formas tradicionales de hacer periodismo. A ello se unen las observaciones de Barreno-Cortés (2019), cuando matiza que además de mejorar las condiciones de los periodistas y la calidad del producto, permite un nuevo tipo de narración periodística de bajo coste. Es más, brinda la posibilidad de nuevas narrativas (López-Hidalgo, 2016), contribuyendo a la producción de contenidos multimedia (Prudkin, 2016) e incluso cambiando la naturaleza del fotoperiodismo (Romero-Tenorio; Buitrago-Echeverry y Echeverry-Blanco, 2017). Si bien, más allá de esta puesta en valor, también hay controversias sobre su utilización, por ejemplo, para la grabación de imágenes en conflictos armados (Postema, 2015).

Hay que tener presente que la grabación de imágenes o sonidos mediante drones y su posterior tratamiento, puede tener implicaciones jurídicas para la privacidad y la protección de datos personales. En este sentido, como señala Aced Félez (2013), uno de los aspectos más importantes del manejo de estos aparatos es su invisibilidad, lo que supone un potencial para el abuso.

Relevante son las medidas encaminadas a la protección de privacidad, como señalan Ntalakas, Dimoulas, Kalliris y Veglis (2017), quienes avisan de que las restricciones éticas, de privacidad y de regulación, tienen grandes implicaciones en el uso de drones con fines periodísticos. Al mismo tiempo, resaltan la importancia de contar con normas básicas para los periodistas. También destacan la trascendencia de directrices como la de utilizar esta tecnología sólo en caso de que ninguna otra medida de recopilación sea posible y la historia tenga interés informativo. Así lo marcan también las reglas básicas para periodistas en el uso de drones de la Professional Society of Drone Journalists.

Tremayne y Clark (2013) insisten en la erosión a la privacidad que suponen los drones equipados con cámara de vídeo, más en una sociedad en la que la aceptación de nuevas formas de vigilancia es prácticamente inevitable. Sobre las implicaciones en la privacidad también reflexionan Cassimally (2014) y Jarvis (2014), al tiempo que abordan los límites éticos que supone el manejo de drones. Ello lleva a Jarvis a plantear cómo usar éticamente esta tecnología por parte de los periodistas a la hora de contar sus historias. Otros autores como Liebes y Kampf (2009) advierten del peligro de caer en el amarillismo a la hora de informar.

El incremento de utilización de drones hace necesario establecer regulaciones tanto en ámbitos internacionales como locales, si bien la disparidad de regulaciones nacionales ha dado lugar a situaciones heterogéneas según los países (Aguado-Guadalupe, 2019). La importancia de contar con un marco regulador adecuado a este respecto ya se venía poniendo de manifiesto por autores como Sánchez-Sierra (2014), quien avisaba de la necesidad de regulación y de las implicaciones del vacío legislativo imperante en muchos países. Si bien, llamaba la atención sobre la importancia de los drones para ayudar a descubrir situaciones que de otro modo permanecerían ocultas a los ojos de los ciudadanos.

Otros autores, como Gallardo-Camacho y Lavín (2016, p. 223), han alertado de la existencia de "grandes trabas legales", que hacen que los trabajos periodísticos que recurren a esta tecnología se limiten a determinados momentos noticiables (catástrofes, principalmente).

A todo ello se une la consideración de la finalidad lucrativa que pueda existir detrás del uso de drones. En este sentido, Waite ve ilícita la utilización del producto del periodismo dron cuando se busca el lucro, incluso en una organización no lucrativa, y aunque no se introduzca publicidad, ya 
que "si hay un enlace de suscripción o un botón de donar esto es suficiente" (Waite: 2013, p. 10). Aspecto que sin duda condiciona su uso para actividad periodística, en cuanto que nos encontramos normalmente ante empresas informativas que tienen finalidad lucrativa.

\section{Metodología}

En primer lugar, se ha delimitado el fenómeno a estudiar, para proceder, de acuerdo con la metodología funcional propuesta por Zweigert y Kötz (1998) a la comprensión de las normas y la comparativa de las medidas adoptadas.

Con ello se ha buscado, en atención a la metodología de derecho comparado propuesta por Pieters (2009), conocer, comprender y comparar las soluciones adoptadas en Estados Unidos y en Europa. Asimismo, se han observado similitudes y diferencias entre lo que se ha identificado en los diversos órdenes de comparación.

Para ello se han seleccionado las principales normativas y códigos de conducta sobre el uso de drones establecidos por los organismos de referencia en esta labor tanto en Estados Unidos como en Europa.

Para realizar el análisis, en lo que respecta a Estados Unidos, se han considerado las normas establecidas por entidades de referencia en políticas de telecomunicaciones relacionadas con avances tecnológicos. De tal manera que se han analizado:

- Los consejos lanzados en 2016 por la National Telecommunications and Information Administration (NTIA), a través del documento Voluntary Best Practices for UAS Privacy, Transparency and Accountability.

- La normativa Operation and Certification of Small Unmanned Aircraft Systems, puesta en marcha por la Federal Aviation Administration, que entró en vigor en 2016.

Han merecido consideración las medidas adoptadas al respecto en California en 2015 (AB865 Invasion of Privacy) y en Texas (HB2167/2015 Relating to certain images captured by an unmanned aircraft), en tanto que condicionan el trabajo de los periodistas a la hora de marcar pautas para proteger la privacidad frente al uso de drones. En el caso de California, por estar dirigida a poner límite a la actividad de los fotógrafos de prensa. En lo que respecta a Texas, por los condicionantes en la toma de imágenes, impidiendo la identificación de personas.

En el caso de Europa, se han contemplado aquellas disposiciones que son de cumplimiento para los diferentes países, formando parte de un marco legislativo común, sin entrar a considerar medidas de carácter más local. Así, se ha considerado:

- El Dictamen sobre la privacidad y la protección de datos en relación con la utilización de aviones no tripulados, elaborado en 2015 por el Grupo de Trabajo del artículo 29 sobre Protección de Datos (creado por la Directiva 95/46/CE y formado por las autoridades europeas de protección de datos).

- La Resolución sobre el uso seguro de los sistemas de aeronaves pilotadas de forma remota (RPAS) en el ámbito de la aviación civil, que fue aprobada por el Parlamento Europeo en su sesión plenaria del 29 de octubre de 2015.

- El dictamen Introduction of a regulatory framework for the operation of unmanned aircraft systems in the open and specific categories (Opinion $n^{\circ} 1 / 2018$ ), emitido por la Agencia Europea de Seguridad Aérea (EASA). 
- El Reglamento (UE) 2016/679 del Parlamento y del Consejo, de 27 de abril de 2016, relativo a la protección de las personas físicas en lo que respecta al tratamiento de datos personales y a la libre circulación de estos.

- El Reglamento (UE) 2018/1139 del Parlamento Europeo y del Consejo, de 4 de julio de 2018, sobre normas comunes en el ámbito de la aviación civil.

- El Reglamento de Ejecución (UE) 2019/947 de la Comisión, de 24 de mayo de 2019, relativo a las normas y los procedimientos aplicables a la utilización de aeronaves no tripuladas.

En lo referente a los códigos de conducta, se han analizado las medidas adoptadas al respecto por la Association for Unmanned Vehicle Systems International (AUVSI) y la Professional Society of Drone Journalists (PSDJ), en tanto que son dos organizaciones de referencia en el sector.

A partir de la normativa seleccionada se ha procedido a analizar:

1. Las similitudes y diferencias en las disposiciones adoptadas en ambos territorios en cuanto a medidas dirigidas a quienes manejen drones con fines periodísticos.

2. Cuáles son las medidas para proteger la privacidad de terceros frente a la toma de imágenes con drones para fines periodísticos.

3. Si se trata de medidas de obligado cumplimiento o si son recomendaciones a merced de la decisión de los periodistas y medios de comunicación.

4. Si hay excepciones que permitan una mayor tolerancia al considerar el uso de drones en atención determinados usos profesionales.

5. Si entre las excepciones profesionales en el uso de drones se contempla la finalidad con fines periodísticos.

\section{Resultados}

En los resultados se analizan los aspectos que han de tenerse en cuenta por los profesionales de la información, según se recogen en las regulaciones y códigos de conducta profesional promovidos para la protección de la privacidad de las personas.

\subsection{Estados Unidos: un modelo basado en recomendaciones y medidas voluntarias, con excepciones}

En Estados Unidos, como apunta Jarvis (2014), el conflicto sobre el uso de drones afecta a las libertades de la primera y cuarta enmienda, en tanto que pudieran usarse para conseguir imágenes en propiedades privadas sin orden judicial. En este sentido, Saldaña (2011) indica que, aunque la Constitución federal de los Estados Unidos no reconoce expresamente un "derecho a la privacidad", el Tribunal Supremo, a lo largo de una extensa y gradual jurisprudencia, lo ha considerado implícito en las garantías de la primera, cuarta, quinta, novena y decimocuarta enmiendas. "En el sistema constitucional norteamericano el derecho a la privacidad es un concepto amplio, donde se han delimitado progresivamente aquellos ámbitos de la vida privada que tienden a preservar los intereses de soledad, secreto, autonomía, individualidad, desarrollo de la personalidad, libertad de elección en asuntos personales, control de la información personal, así como el sustrato esencial de la inviolable dignidad humana" (Saldaña, 2011, p. 310).

El incremento producido en el uso de drones entre los diversos sectores profesionales, y muy especialmente por los periodistas, ha venido produciendo preocupación y ha llevado a la adopción 
de medidas por parte de los legisladores. De manera que ya en 2014 cuarenta y tres estados tenían promulgada legislación sobre drones, y otros cinco contaban con proyectos de ley (Bohm, 2013).

En dicha línea de actuación, en marzo de 2015, la National Telecommunications and Information Administration (NTIA) anunció que estaba buscando aportaciones sobre la privacidad, la transparencia y las cuestiones de responsabilidad, en relación con el uso comercial y privado de los sistemas de aeronaves no tripuladas. Dicho anuncio se produjo en respuesta a un Memorando Presidencial, emitido el 15 de febrero de 2015, para iniciar ese proceso de consultas con todos los sectores interesados, y en el que, explícitamente, se subrayaba la necesidad de abordar los retos que los drones planteaban para la privacidad (Pauner Chulvi, 2016).

En junio de 2015, en Texas, se aprueba la ley HB2167/2015 Relating to certain images captured by an unmanned aircraft. En la misma no se permite fotografiar con un dron propiedades privadas sin autorización, si bien se consideran 21 supuestos en los que es lícito capturar imágenes utilizando drones. Entre lo contemplado en dichos supuestos, es destacable que se permite capturar imágenes con drones que se utilizan para ciertas profesiones, si bien ninguna persona puede ser identificable en las imágenes capturadas. Es posible el uso "para un propósito de desarrollo e investigación profesional o académico, o para otro propósito académico por parte de una persona en representación de una institución de educación superior o una institución independiente o privada de educación superior". Al mismo tiempo, se establecen matices para la captura de imágenes: "Desde una altura no más de ocho pies del suelo en un lugar público, si la imagen es capturada sin medios electrónicos o mecánicos para amplificarla más allá de la percepción humana normal”. Ello imposibilita el uso de drones más allá de la toma de planos generales.

En el caso de California, en la sección 1708.8 (b) del California Civil Code, se prohíbe el uso de dispositivos para la grabación de imágenes y sonidos de manera ofensiva para una persona, en actos privados, personales y actividades familiares. De tal manera que un dron no puede capturar detalles íntimos de una persona que tiene una expectativa razonable de privacidad. Asimismo, en la sección 1708.8 (f) se contempla la sanción en el caso de contraprestación o remuneración monetaria, o de otro tipo, por los derechos de la imagen o sonido obtenido ilegalmente, violando lo contemplado en las subdivisiones (a), (b) o (c) de la sección 1708.8.

En 2015 se aprobó una enmienda al código civil estatal (AB856 Invasion of Privacy), con el fin de considerar un delito contra la privacidad el uso de drones sobre la propiedad ajena sin la debida autorización. La medida se dirige a poner límite a las actividades de los paparazzi, estableciéndose que se trate como un delito el vuelo de cualquier dron que se adentre en terreno ajeno para espiar la vida privada de las personas. Las penas por invasión de privacidad implican responsabilidades por daños generales y por daños punitivos, debiendo considerarse si hay propósito comercial. Las multas van de 5.000 a 50.000 dólares.

Más allá de las medidas adoptadas en los estados de Texas y California, en mayo de 2016, la National Telecommunications and Information Administration aprobó una serie de consejos sobre privacidad para tener en cuenta cuando se quiere volar un dron, tanto si es comercial como no comercial, a través del documento Voluntary Best Practices for UAS Privacy, Transparency and Accountability. Dichas medidas voluntarias se desarrollaron con el consenso de diversas organizaciones dentro de la industria dron y compañías que desarrollan programas con estos dispositivos, como Amazon o Alphabet (Google). Esta guía recomienda a los operadores que respeten la privacidad de terceros que pueda ser violada con el uso de drones. De este modo se pretende evitar la difusión o uso de datos personales de terceros, con fines comerciales o de marketing, sin el consentimiento expreso del individuo en cuestión. 
Para ello, la agencia recomienda prácticas que garantizan una mayor privacidad, si bien son de carácter voluntario y no pueden limitar las libertades garantizadas en la Constitución, ni reemplazar las leyes existentes a nivel local, estatal o federal. Entre dichas pautas están:

1. Restringir la recopilación persistente y continua de datos sobre individuos.

2. Avisar a terceros de la toma de fotos y vídeos que les puedan afectar.

3. No violar la privacidad tomando fotos, videos o datos si no hay una buena razón para ello.

4. Procurar no volar sobre propiedad privada sin permiso.

5. Proteger la información confidencial que afecta a terceros ante pérdidas y robos.

6. Se solicita a los operadores de drones minimizar las operaciones sobre o dentro de la propiedad privada sin el consentimiento del propietario o de la autoridad legal apropiada.

7. Tener una política detallada de recopilación de datos y limitarse a lo que se describe en esa política.

8. Los operadores de drones han de evitar retener los datos más tiempo del razonablemente necesario y han de dar a las personas el control sobre los datos que les conciernen, borrando los datos si la persona lo solicita.

9. Hay que evitar usar o compartir datos recopilados con fines de marketing sin el consentimiento del interesado.

10. No divulgar datos si no es necesario para cumplir el propósito.

El documento Voluntary Best Practices for UAS Privacy, Transparency and Accountability dedica además la sección $\mathrm{V}$ a las empresas informativas, contemplando expresamente que la recopilación de noticias es una actividad fuertemente protegida por la legislación en Estados Unidos, incluida la Primera Enmienda de la Constitución. Al mismo tiempo recuerda la importancia de una prensa independiente para que el público esté bien informado. Precisamente, para garantizar el acceso a la información por parte de los ciudadanos, establece que las observaciones recogidas en el documento no se aplicarán a los reporteros y agencias de noticias, que podrán usar esta tecnología dron como cualquier otra comparable para capturar, almacenar o usar datos e imágenes en espacios públicos. Si bien matiza que han de operar bajo las normas y estándares éticos de las organizaciones informativas y de las leyes federales y estatales.

Por otra parte, en agosto de 2016, entró en vigor en Estados Unidos la normativa sobre el uso de drones con fines comerciales Operation and Certification of Small Unmanned Aircraft Systems. Esta regulación, conocida como Part 107, en referencia a la sección que ocupa dentro del código de transporte de Estados Unidos, se aprobó por parte de la Federal Aviation Administration (FAA). En la misma se establecen los requisitos mínimos para explotar este tipo de aparatos con fines comerciales. Se trata de una normativa que fija las bases para el uso comercial de los drones con un peso de hasta 55 libras y que sirve de guía en el uso de drones para recopilación de noticias en todo Estados Unidos. Si bien, esta nueva normativa no trata cuestiones de protección de datos y privacidad. A este respecto, la FAA se ha limitado a remitir a los operadores de este tipo de aparatos a las directrices recogidas en el documento Voluntary Best Practices for UAS Privacy, Transparency and Accountability.

En 2017, el Instituto Poynter, tras impartir formación a periodistas sobre el uso ético y seguro de drones, elaboró un código de ética periodística, en el que se pedía respeto a la privacidad. Para ello contó con el apoyo de la Asociación Nacional de Fotógrafos de Prensa, del Laboratorio de 
periodismo con drones de la Universidad de Nebrasca-Lincoln, del Centro de Ética de Periodismo de la Universidad de Wisconsin y de DJI (fabricante mundial de vehículos aéreos no tripulados). Las medidas contempladas estaban en consonancia con la Sociedad de Periodistas Profesionales de Estados Unidos, en cuyo código de ética se indica que ha de equilibrarse la necesidad de informar al público con los posibles daños e incomodidades que su publicación pueda causar. También pide tener presente que la búsqueda de las noticias no es una licencia para la arrogancia o la intrusión indebida. En el código ético del Instituto Poynter se indica a los medios de comunicación que se nieguen a publicar imágenes que puedan contener evidencias de haber violado las regulaciones de la FAA. En todo caso, si las imágenes tienen un valor informativo alto habrá de explicarse claramente por qué han de publicarse, a pesar de las técnicas utilizadas para conseguirlas. Asimismo, se pide garantizar el respeto por la integridad del momento en que se están tomando las imágenes, no contribuyendo por parte del periodista a alterar o influir en los eventos.

\subsection{Marco europeo para legisladores, reguladores, fabricantes y usuarios de drones}

La Comisión Europea ha buscado establecer un marco normativo que regule de forma uniforme las operaciones de los drones civiles en todo el espacio comunitario, con el fin de evitar distintas regulaciones fragmentadas de los países miembros (Aguado-Guadalupe, 2019). El objetivo es doble, permitir que la industria europea se convierta en un líder mundial en el mercado de esta tecnología emergente y, al mismo tiempo, garantizar que se adopten todas las medidas necesarias para proteger los derechos de los ciudadanos de la Unión Europea.

En la protección de dichos derechos es esencial el derecho a la privacidad, partiendo de que Europa dispone de un sistema que reconoce el respeto a la vida privada y familiar en el art. 7 de la Carta de los Derechos Fundamentales de la Unión Europea; y el derecho a la protección de datos personales como un derecho fundamental, establecido en el art. 8 de la misma. Además, se cuenta con el Reglamento (UE) 2016/679 del Parlamento Europeo y del Consejo, que es más rígido en la protección de datos personales que la derogada Directiva de 1995 (Unión Europea, 1995). En este sentido, Jourová (2016) señala que la reforma del Reglamento se centra en tres aspectos principales: resguardar el derecho fundamental a la protección de datos, independientemente de cómo se desenvuelvan en el futuro la tecnología y el entorno digital; aumentar la confianza en el entorno digital; e incrementar la actividad económica.

Por otra parte, la Directiva 2002/58/CE de Privacidad y Comunicaciones Electrónicas, modificada por la 2009/136/CE, recoge que los drones pueden ser utilizados como proveedores de servicios de comunicaciones electrónicas a disposición pública.

No obstante, debido a los riesgos que comporta el uso de drones para la protección de datos y privacidad de las personas, el Grupo de Trabajo del artículo 29 sobre Protección de Datos (creado por la Directiva 95/46/CE y formado por las autoridades europeas de protección de datos), elaboró en 2015 el Dictamen sobre la privacidad y la protección de datos en relación con la utilización de aviones no tripulados (drones). Se trata del primer dictamen conjunto sobre drones en el que se analiza la incidencia y los riesgos que la utilización de estos aparatos plantea para la privacidad y protección de datos. Estos riesgos, como se apunta en el Dictamen, se producen por la capacidad de dichas máquinas de recoger y procesar datos personales, tales como imágenes, sonidos o datos de geolocalización asociados a una persona identificada o identificable.

En dicho texto se recogen directrices para interpretar las normas comunitarias y nacionales de protección de datos. De manera que se incluyen recomendaciones dirigidas a legisladores, reguladores del sector, fabricantes y a quienes manejan los drones: 
a) Los legisladores y reguladores deben promover tanto en el ámbito nacional como en el europeo un marco que garantice no sólo la seguridad en vuelo, sino el respeto por todos los derechos fundamentales de las personas.

b) Los fabricantes han de adoptar medidas de privacidad desde el diseño y realizar evaluaciones de impacto en la protección de datos.

c) Para concienciar a los usuarios, en el caso de dispositivos de pequeñas dimensiones ha de incluirse información suficiente relativa al potencial intrusivo de estas tecnologías y, cuando sea posible, mapas que identifiquen claramente dónde está permitido su uso.

d) En cuanto a los operadores, se recomienda evitar en lo posible volar sobre zonas privadas y edificios, incluso cuando esté permitido su uso.

e) Se indica a las autoridades de los distintos Estados que la recolección de datos personales por parte de autoridades de orden público, que utilicen estas aeronaves en sus funciones de vigilancia y control, no debe permitir el rastreo constante. En caso de que este fuera necesario, debe quedar restringido al marco de las investigaciones encaminadas a garantizar el cumplimiento de las normas legales.

En el Dictamen también se recogen una serie de obligaciones que deben aplicarse antes de utilizar un dron. Entre ellas está verificar si es necesaria una autorización específica de aviación civil; encontrar el criterio más adecuado para que el tratamiento sea legítimo; o cumplir con los criterios de transparencia, proporcionalidad, minimización en la captura de datos o limitación del propósito para el cual se procesan.

Este Dictamen ha servido de base para redactar la Resolución sobre el uso seguro de los sistemas de aeronaves pilotadas de forma remota (RPAS) en el ámbito de la aviación civil, que fue aprobada por el Parlamento Europeo, en su sesión plenaria del 29 de octubre de 2015.

Dicha resolución ha abierto la puerta a los usos de drones civiles con fines comerciales y profesionales. Si bien considera que la protección de datos y la privacidad son claves para fomentar el apoyo al empleo de drones civiles. Por ello, pide respetar la Directiva 95/46/CE sobre protección de datos personales; así como el derecho al respeto de la vida privada, consagrado en el artículo 7 de la Carta de los Derechos Fundamentales de la Unión Europea; y el derecho a la protección de los datos de carácter general, consagrado en el artículo 8 de la Carta de los Derechos Fundamentales de la UE y el artículo 16 del Tratado de Funcionamiento de la Unión Europa. De igual manera, pide la incorporación de garantías sobre privacidad y protección de datos, de conformidad con los principios de necesidad y transparencia.

Esta Resolución apuesta por crear un marco legislativo común, que garantice que todas las partes implicadas realizan un tratamiento adecuado de los datos. Considera que las autoridades de protección de datos de los Estados miembros han de cooperar en este sentido, al tiempo que pide que se aplique minuciosamente la legislación sobre protección de datos, de manera que se alivie la incertidumbre en los ciudadanos en relación con su intimidad. Recomienda que se mantengan conversaciones entre la UE, los responsables políticos, reguladores, industria, Pymes, ciudadanos, ONGs y autoridades policiales, para abordar los desafíos en protección de datos. Demanda un marco jurídico claro sobre el uso de cámaras y sensores, especialmente en el caso de drones comerciales y privados, para garantizar el derecho a la vida privada y protección de datos.

En el año 2018, la Agencia Europea de Seguridad Aérea (EASA) emitió el dictamen Introduction of a regulatory framework for the operation of unmanned aircraft systems in the open and specific categories (Opinion $\mathrm{n}^{0} 1 / 2018$ ), con la intención de armonizar los reglamentos de operaciones en 
Europa y crear un mercado común de la UE para drones. Sus prioridades son: a) mantener a los drones alejados de aviones tripulados, proteger personas e infraestructuras críticas; b) mantener los drones a una distancia prudencial de reactores nucleares, bases militares y oleoductos; c) garantizar la privacidad mediante una separación adecuada respecto de las áreas residenciales; y d) proteger el medio ambiente reduciendo el nivel de ruido.

Este dictamen de la EASA establece límites generales, al tiempo que permite un alto grado de flexibilidad a los estados miembros para regular, sirviendo de base para un marco regulatorio más amplio. Esta normativa es el punto de partida para la creación de un mercado europeo de drones más uniforme.

En agosto de 2018 se publicó el Reglamento (UE) 2018/1139 del Parlamento Europeo y del Consejo, de 4 de julio de 2018, sobre normas comunes en el ámbito de la aviación civil. Se trata de una norma que regula la aviación civil en general, al entender que las aeronaves no tripuladas comparten el espacio aéreo con las tripuladas. Entre los objetivos que se persiguen está también garantizar el cumplimento de derechos en la Unión Europea. En concreto, el respeto a la vida privada y el derecho a la protección de datos de carácter personal. Es destacable la matización establecida al respecto de los drones en el artículo 56.8. En el mismo dice que lo dispuesto en la sección VII de Aeronaves no tripuladas se entenderá sin perjuicio de la posibilidad de que los Estados miembros promulguen normas nacionales para someter a determinadas condiciones la operación de aeronaves no tripuladas por razones ajenas al ámbito de aplicación del presente Reglamento. En particular por razones de seguridad pública o de protección de la privacidad y de los datos personales con arreglo al Derecho de la Unión.

El 11 de junio de 2019, el Diario Oficial de la Unión Europea publicó el Reglamento de Ejecución (UE)2019 /947 de la Comisión, de 24 de mayo de 2019, relativo a normas y procedimientos aplicables a la utilización de aeronaves no tripuladas (drones). Esta legislación permite igualar la normativa de todos los países miembros. Además, supone una ayuda a los operadores de drones para conocer las operaciones permitidas y prohibidas, así como los trámites que se requieren para los permisos necesarios en cualquier país de la UE. Es destacable el requisito de registrarse para que el operador de una aeronave no tripulada dotada de un sensor que pueda captar datos personales, tenga en cuenta el riesgo que ello supone para la privacidad y la protección de dichos datos.

\subsection{Códigos de conducta para el uso de drones con fines periodísticos}

El incremento del uso de drones ha propiciado la aprobación de códigos de conducta para orientar a los profesionales en el uso de drones y en las medidas a seguir para garantizar la privacidad de los ciudadanos. Importante a este respecto son las medidas adoptadas por la Association for Unmanned Vehicle Systems International (AUVSI) y la Professional Society of Drone Journalists (PSDJ).

La Association for Unmanned Vehicle Systems International, con más de 7500 miembros de más de 60 países, es la organización sin ánimo de lucro más grande del mundo dedicada a promover la comunidad de los sistemas no tripulados. De ella forman parte representantes de las compañías más importantes de este sector. Entre sus acciones está la elaboración de un Código de conducta relativo a la operación de los Unmanned Aerial Vehicle (UAV) o vehículos aéreos no tripulados.

El código tiene tres apartados: seguridad, profesionalidad y respeto, haciendo incidencia en que ha de asegurarse dicho respeto a todos los usuarios del espacio aéreo y a la privacidad de las personas. A este respecto contempla el cumplimiento de las leyes nacionales, estatales y locales; así como de las ordenanzas, acuerdos y restricciones relativas a las operaciones con drones. También se establece la necesidad de respetar la privacidad de las personas, los derechos de los usuarios en el espacio aéreo, y apoyar la mejora del conocimiento y educación pública sobre operaciones con drones. Todo 
ello partiendo de la valoración de que no es posible otra medida de recopilación y que se trata de una historia de interés informativo.

Por su parte, la Professional Society of Drone Journalists, primera organización internacional dedicada a establecer un marco ético, educativo y tecnológico en el ámbito del uso de drones en periodismo, que actualmente está presente en 35 países, trabaja para promover el uso seguro y responsable de estos aparatos. Para ello ha adoptado un código de conducta, en el que se recomienda considerar por parte de los profesionales del periodismo aspectos como la ética, la noticiabilidad, la seguridad, el respeto a las leyes, los espacios públicos y la privacidad. Entre los factores a considerar se encuentran:

1. Valor informativo. Valorar la importancia periodística de la investigación como para arriesgarse a utilizar un dron. No utilizarlo si la información se puede obtener por otros medios más seguros.

2. Seguridad. Un operador de drones debe ser entrenado adecuadamente. El equipo en sí debe estar en una condición adecuada. El dron debe ser volado garantizando la seguridad.

3. Espacios públicos. El operador de drones debe cumplir con la regulación que sea aplicable al espacio aéreo donde se opera. El dron debe ser operado de la manera que sea menos perjudicial para la población general en un entorno público.

4. Privacidad. El dron debe ser operado de manera que no comprometa innecesariamente la privacidad de las figuras no públicas. A ser posible han de registrarse sólo imágenes de actividades en espacios públicos, y evitar imágenes de particulares en espacios privados que ocurran fuera del alcance de la investigación.

5. Ética. El periodista que utiliza dron ha de atenerse a los códigos de conducta profesionales imperantes para el resto de la profesión.

\section{Conclusiones}

Tanto en Estados Unidos como en Europa se ha procedido a adoptar medidas para proteger la privacidad frente al uso de drones con fines periodísticos. Si bien, se ha apreciado, en consonancia con lo apuntado por Sacco (1991), que hay soluciones normativas diferentes para la misma situación. Ello da muestra, como señala Pérez Miras (2018), de dos percepciones, dando lugar a dos modelos conceptuales de regulación. Las soluciones han estado condicionadas por la distinta noción de privacidad con la que se designa la protección de la esfera privada de la persona en uno y otro territorio, en línea con las observaciones de autores como Saldaña (2007). Ha incidido que Estados Unidos tiene muy presente que la recopilación de noticias es una actividad fuertemente protegida por la legislación, incluida la $1^{\circ}$ Enmienda de la Constitución. Europa, por su parte, tiene un sistema más garantista, que reconoce el derecho a la protección de datos personales como un derecho fundamental.

En el caso de Estados Unidos, las medidas adoptadas para proteger la privacidad frente al uso de drones pasan fundamentalmente por los consejos sobre privacidad adoptados en 2016 por parte de la agencia National Telecommunications and Information Administration. Se trata de recomendaciones, donde prevalece la voluntariedad del usuario del dron frente al derecho de terceros a la privacidad. Se contempla un tratamiento especial en el caso de la prensa, para garantizar el acceso a la información por parte de los ciudadanos. De manera que los periodistas pueden usar la tecnología dron como cualquier otra a la hora de recopilar información, si bien han de atenerse a las normas éticas establecidas y las leyes federales y estatales existentes. Frente a dichas medidas hay excep- 
ciones, como los casos de los estados de Texas y California, donde se cuenta con normativas en las que se considera un delito contra la privacidad el uso de drones sin la debida autorización, si bien se contemplan excepciones.

En el caso de Europa, debido a los riesgos que comporta el uso de drones para la protección de la privacidad, el Grupo de Trabajo del artículo 29 elaboró en 2015 un Dictamen sobre privacidad y protección de datos con relación a la utilización de aviones no tripulados. Dicho texto contempla obligaciones a cumplir antes de utilizar un dron, así como criterios de transparencia, proporcionalidad, minimización en la captura de datos y limitación del propósito para el cual se procesan. Este dictamen sirvió de base para la Resolución sobre el uso seguro de los sistemas de aeronaves pilotadas de forma remota de 2015 , donde se apuesta por un marco común de garantías, que alivie la incertidumbre de los ciudadanos en relación con su privacidad.

A ello se une el dictamen emitido por la Agencia Europea de Seguridad Aérea en 2018 (Opinion $n^{\circ} 1 / 2018$ ), entre cuyas prioridades está garantizar la privacidad mediante una separación adecuada de las áreas residenciales. Además, ese mismo año 2018 se publicó el Reglamento sobre normas comunes en el ámbito de la aviación civil, entre cuyos objetivos está el respeto a la vida privada y el derecho a la protección de datos personales.

Asimismo, en 2019 se publicó el Reglamento de Ejecución (UE)2019/947 de la Comisión relativo a normas y procedimientos aplicables a la utilización de aeronaves no tripuladas, que permite igualar la normativa de todos los países miembros y establece la obligatoriedad de registro si se usan drones dotados de un sensor que pueda captar datos personales, teniendo en cuenta el riesgo que ello supone para la privacidad y la protección de dichos datos.

Importante referencia igualmente son los códigos de conducta de organizaciones como Association for Unmanned Vehicle Systems International y la Professional Society of Drone Journalists, que hacen incidencia en la privacidad de las personas, la ética, la noticiabilidad, la seguridad, el respeto a las leyes y los espacios públicos. Al tiempo que piden que se valore por parte de los periodistas si es posible otra medida de recopilación de datos e imágenes y si se trata de una historia de interés informativo.

Se puede observar que el marco regulador de Estados Unidos en cuanto a privacidad frente al uso de drones se asienta más en recomendaciones de cumplimento voluntario. En tanto que la normativa europea se sitúa en un sistema más garantista en el derecho a la protección de datos personales.

\section{Bibliografía}

AB 856 Invasion of privacy. Assembly Bill No 856, Chapter 521. California, EE.UU. Approved by Governor October 06, 2015. Filed with Secretary of State October 06, 2015. http://leginfo. legislature.ca.gov/faces/billNavClient.xhtml?bill_id=201520160AB856

Aced Félez, E. (2013). Drones: una nueva era de la vigilancia y de la privacidad. Red seguridad.com, 60, 48-57.

Aguado-Guadalupe, G. (2019). Repercusiones en el ejercicio del periodismo de la regulación del uso de drones en Europa. En J. Flores, (Ed.), Tecnologías del ecosistema periodístico (pp. 117-136). Comunicación Social Ediciones y Publicaciones.

Association for Unmanned Vehicle Systems International. Code of Conduct. https://www.auvsi. org/code-conduct 
Barreno-Cortés, J. (2019). La miniaturización de los drones y sus múltiples usos periodísticos. En J. Flores, (Ed.), Tecnologías del ecosistema periodístico (pp. 97-115). Comunicación Social Ediciones y Publicaciones.

Bohm, A. (2013). Status of Domestic Drone Legislation in the States. American Civil Liberties Union. https://www.aclu.org/blog/technology-and-liberty/status-domestic-dronelegislationstates

Carta de los Derechos Fundamentales de la Unión Europea (200/C/ 364/01). Diario Oficial de las Comunidades Europeas C34/1. 18-12-2000. https://www.europarl.europa.eu/charter/pdf/text_es.pdf

Cassimally, K. A. (28 de febrero de 2013). Brace Yourselves, Drone Journalism Is Coming. Scientific American. https://blogs.scientificamerican.com/incubator/brace-yourselves-dronejournalism-is-coming/

Ciobanu, M. (3 de mayo de 2016). Are drones a new avenue for data journalism? Journalim.oc.uk. https://www.journalism.co.uk/news/are-drones-a-new-avenue-for-data-journalism-/s2/a634331/

Cohen, J.E. (2000). Examined Lives: Informational Privacy and the Subject as Object. Stanford Law Review, 52, 1373-1438.

Corcoran, M. (2014). Drone Journalism: Newsgathering applications of Unmanned Aerial Vehicles UUAVs) in covering conflict, civil unrest, and disaster. Australian Broadcasting Corporation. https://cryptome.org/2014/03/drone-journalism.pdf.

European Commission. (2014c, Apri18). Communication from the Commission to the European Parliament and the Council. A new era for aviation. Opening the aviation market to the civil use of remotely piloted aircraft systems in a safe and sustainable manner (COM (2024) 0207). Brussels.

Federal Aviation Administration (2016). Operation and Certification of Small Unmanned Aircraft Systems (Part. 107). Billing Code 4910-13-P, US. https://www.faa.gov/uas/media/ RIN_2120-AJ60_Clean_Signed.pdf

Fernández-Barrero, M. A. (2018). Periodismo y drones. Retos y oportunidades del uso de drones para la narración informativa en España. Doxa Comunicación, 26, 35-58.

Fried, C. (1967-1968). Privacy. The Yale Law Journal, 77, 475-493.

Gallardo-Camacho, J. y Lavín, E. (2016). Uso de drones con fines informativos en empresas de TV en España. El profesional de la información, 25 (2), 217-225. http://dx.doi.org/10.3145/ epi.2016.mar.08

Gynnild, A. (2014). The Robot Eye Witness. Digital Journalism, 2 (3), 334-343. https://doi.org/10 $.1080 / 21670811.2014 .883184$

Goldberg, D., Corcoran, M. y Picard, R. G. (2013). Remotely piloted aircraft systems and journalism: Opportunities and challenges of drones in news gathering. Reuters. Institute for the Study of Journalism, Universidad de Oxford, 1-34.

Goldman, E. (2006). A Coasean Analysis of Marketing. Wisconsin Law Review, 1151-1221.

Grupo de Trabajo artículo 29 sobre protección de datos. Dictamen 01/2015 sobre la privacidad y la protección de datos en relación con la utilización de aviones no tripulados (drones). Adoptado el martes 16 de junio de 2015. https://www.aepd.es/media/criterios/wp231-en-es.pdf 
Hirsch, D.D. (2006). Protecting the Inner Environment: What Privacy Regulation can learn from environmental Law. Georgia Law Review 41 (1) 8-10.

Holton, A. E., Lawson, S. y Love, C. (2015). Unmanned aerial vehicles. Journalism practice, 9 (5), 634-655. https://doi.org.10.1080/21670811.2017.1279019

Jarvis, J. C. (2014). The Ethical Debate of Drone Journalism: Flying into The Future of Reporting. Research Papers. Paper 475. http://opensiuc.lib.siu.edu/gs_rp/475

Jourová, V. (2016). "How will the EU's reform adapt data protection rules to new technological developments?". European Commission, Justice and Consumers. http://ec.europa.eu/newsroom/ just/item-detail.cfm?item_id=52404

Liebes, T.y Kampf, Z. (2009). Performance Journalism: The Case of Media`s Coverage of War and Terror. The Communication Review, 12 (3), 239-249. https://doi. org/10.1080/10714420903124135

López-Hidalgo, A. (2016). El periodismo que contará el futuro. Chasqui, Revista Latinoamericana de Comunicación, 131, 239-256.

Miller, A. R. (1971). The Assault on Privacy: Computers, Data Banks, and Dossiers. An Arbor: University of Michigan Press.

Ntalakas, A., Dimoulas, Ch., Kalliris, G. y Veglis, A. (2017). Drone Journalism: Generating Immersive Experiences. Journal of Media Critiques, 13 (11), 187-199. https://doi.org/10.17349/ jmc117317

National Telecommunications and Information Administration (2016). Voluntary Best Practices for UAS Privacy, Transparency and Accountability. https://www.ftc.gov/system/files/documents/ public_comments/2016/10/00008-129242.pdf

Opinion $n^{\circ} 1 / 2018$. "Introduction of a regulatory framework for the operation of unmanned aircraft systems in the open and specific categories". European Aviation Safety Agency. Related NPA/CDR: 2017-05-RMT-0230. https://www.easa.europa.eu/sites/default/files/dfu/Opinion\%20 No\%2001-2018.pdf

Padgett, G.E. (1985). Codes should address exploitation of grief by photographers. Journal of Mass Media Ethics, 1 (1), 50-56. https://doi.org/10.1080/08900528509358255

Pauner Chulvi, C. (2016). El uso emergente de drones civiles en España. Estatuto jurídico e impacto en el derecho a la protección de datos. Revista de Derecho Político, 95, 83-116. https:// doi.org/10.5944/rdp.95.2016.16233

Pérez Miras, J. (2018). El derecho a la protección de datos y a la privacidad. Una perspectiva comparada entre la Unión Europea y Estados Unidos. Tesis Doctoral. Universidad de Sevilla.

Postema, S. (2015). News Drones: An Auxiliary Perspective. Edinburgh Napier University. https:// doi.org/10.13140/RG.2.1.4012.1045

Poynter (2017). Poynter workshops produce new drone journalism ethics policy. https://www. poynter.org/tech-tools/2017/poynter-workshops-produce-new-drone-journalism-ethics-policy-2/

Professional Society of Drone Journalists. Code of Ethics for Drone Journalism. https:// ethicaljournalismnetwork.org/tag/professional-society-of-drone-journalists

Prosser W. (1960). Privacy. California Law Review, 48(3), 383-423. 
Prudkin, G. (2016). El Periodismo Drone: contextualización histórica y posibles usos periodísticos. Comunicação \& Inovação, 17 (33), 7-21.

Reglamento (UE) 2018/1139 del Parlamento Europeo y del Consejo, de 4 de julio de 2018, sobre normas comunes en el ámbito de la aviación civil y por el que se crea una Agencia de la Unión Europea para la Seguridad Aérea y por el que se modifican los reglamentos (CE) $n^{\circ} 2111 / 2005$, (CE) no 1008/2008, (UE) nº96/2010, (CE) no 376/2014 y las Directivas 2014/30/UE y 2014/53/ UE del Parlamento Europeo y del Consejo y se derogan los Reglamentos (CE) n $n^{\circ}$ 552/2004 y (CE) n2 216/2018 del Parlamento Europeo y del Consejo y el Reglamento (CEE) no 3922/91 del Consejo. DOUEL n ${ }^{\circ} 212$ de 22 de agosto de 2018. http://noticias.juridicas.com/base_datos/ Admin/627064-regl-2018-1139-ue-de-4-de-jul-normas-comunes-en-el-ambito-de-la-aviacion.html

Relating to certain images captured by an unmanned aircraft. HB 2167/2015. Passed: 2015-0609. Texas. https://legiscan.com/TX/text/HB2167/2015

Resolución del Parlamento Europeo, de 29 de octubre de 2015, sobre el uso seguro de los sistemas de aeronaves pilotadas de forma remota (RPAS), comúnmente conocidas como vehículos aéreos no tripulados (UAV) en el ámbito de la aviación civil. Estrasburgo. http://www.europarl.europa. eu/doceo/document/TA-8-2015-0390_ES.html?redirect

Reglamento (UE) 2016/679 del Parlamento Europeo y del Consejo de 27 de abril de 2016 relativo a la protección de las personas físicas en lo que respecta al tratamiento de datos personales y a la libre circulación de estos datos y por el que se deroga la Directiva 95/46/CE (Reglamento general de protección de datos). Diario Oficial de la Unión Europea, 4.5.2016. https://www.boe.es/ doue/2016/119/L00001-00088.pdf

Reglamento de Ejecución (UE) 2019/947 de la Comisión de 24 de mayo de 2019 relativo a las normas y los procedimientos aplicables a la utilización de aeronaves no tripuladas. Diario Oficial de la Unión Europea, 11.6.2019. https://www.boe.es/doue/2019/152/L00045-00071.pdf

Romero-Tenorio, J. M., Buitrago-Echeverry, C. y Echeverry-Blanco, M.R. (2017). ¿Deslizarse o sumergirse en la interfaz? El periodismo dron y la maquetación ergonómica del espacio. Estudios sobre el Mensaje Periodístico, 23 (1), 257-272. http://dx.doi.org/10.5209/ESMP.55595

Saldaña, M.N. (2012). «The right to privacy». La génesis de la protección de la privacidad en el sistema constitucional norteamericano, el centenario legado de Warren y Brandeis. Revista de Derecho Politico, 85, 195-240. https://doi.org/10.5944/rdp.85.201112.10723

Saldaña, M. N. (2011). El derecho a la privacidad en los Estados Unidos: aproximación diacrónica a los intereses constitucionales en juego. Teoría y Realidad Constitucional, 28, 279-312.

Saldaña, M.N. (2007). La protección de la privacidad en la sociedad tecnológica. El derecho constitucional a la privacidad de la información personal en los Estados Unidos. Araucaria. Revista Iberoamericana de Filosofía, Política y Humanidades, 9 (18). 85-115.

Sacco, R. (1991). Legal Formants: A Dynamic Approach to Comparative Law. The American Journal of Comparative Law. 39(1), 1-34. https://doi.org/10.23007/840669

Sánchez-Sierra, A. (2014). El periodismo de drones y su regulación a debate en diferentes países. Periodismo Ciudadano. https://www.periodismociudadano.com/el-periodismo-drone-y-suregulacion-a-debate-en-diferentes-paises/

Suárez-Gonzalo, S. (2017). Big Social Data: límites del modelo notice and choice para la protección de la privacidad. El profesional de la información, 26 (2), 283-292. https://doi. org/10.3145/epi.2017.mar.15 
Schwartz, P.M. (1999). Privacy and Democracy in Cyberspace. Vanderbilt Law Review, 52, 16091701.

Schwartz, P.M. (2013). The EU-U.S. Privacy Collision: A Turn to Institutions and Procedures. Harvard Law Review, 126. http://cdn.harvardlawreview.org/wp-content/uploads/ pdfs/vol126_ schwartz.pdf

Solove, D. J. (2002). Conceptualizing Privacy. California Law Review, 90, 1087-1155.

Solove, D. J. (2008). Understanding privacy. Cambridge: Harvard University Press.

Torres-Simón, F.J. (2016). El dron aplicado al sector audiovisual. Uso de RPAS en la filmación aérea. Editorial Tébar Flores.

Tremayne, M. y Clark, A. (2013). New Perspectives from The Sky: Unmanned Aerial Vehicles and Journalism. Digital Journalism, 2 (2), 232-246. https://doi.org/10.100/21670811.2013.805039

Waite, M. (2013). Drone journalism. Investigative reporters and editors. IRE Journal, 36(3), 9-13.

Warren, S. y Brandeis, L.D. (1995). El derecho a la intimidad, ed. de B. Pendás y P. Baselga. Madrid: Civitas.

Whitman, J.Q. (2004). The Two Western Cultures of Privacy: Dignity Versus Liberty. Yale Law Journal, 113, 1151-1221.

Zweigert, K. y Kötz, H. (1998). Introduction to Comparative Law. Oxford: Clarendon Press. 